\title{
Les occupations rurales antiques de la Plaine d'Argentan
}

$n^{\circ} 3112$

Guy Leclerc

\section{OpenEdition}

Journals

Édition électronique

URL : http://journals.openedition.org/adlfi/17130

ISSN : 2114-0502

Éditeur

Ministère de la culture

\section{Référence électronique}

Guy Leclerc, "Les occupations rurales antiques de la Plaine d'Argentan », ADLFI. Archéologie de la France - Informations [En ligne], Basse-Normandie, mis en ligne le 23 mars 2016, consulté le 25 avril 2019. URL : http://journals.openedition.org/adlfi/17130

Ce document a été généré automatiquement le 25 avril 2019

(c) Ministère de la Culture et de la Communication, CNRS 


\title{
Les occupations rurales antiques de la Plaine d'Argentan
}

$n^{\circ} 3112$

\author{
Guy Leclerc
}

1 L'opération de prospection 2013 marquait la fin des investigations menées dans la Plaine d'Argentan depuis 2008; elle s'est intéressée aux communes situées en bordure de l'espace sédimentaire. Au sud-ouest, sur Loucé, Joué-du-Plain et Sevrai, les occupations antiques semblent alignées le long de l'itinéraire Jort-Jublains et des voies secondaires. Par contre, le nord-est de la Plaine en bordure de la forêt de Gouffern (Juvigny-sur-Orne, Sai, Urou-et-Crennes) est apparu dépourvu d'implantations suggérant ainsi une extension de l'espace boisé à l'époque antique.

Quantitativement, 17 entités inédites ont été répertoriées dans l'espace prospecté avec la répartition suivante :

Loucé : 4

4 Sevrai : 4

5 Joué-du-Plain : 4

6 Sai : 1

7 Juvigny-sur-Orne : 0

8 Urou-et-Crennes : 0

9 Il faut y ajouter 4 sites identifiés sur les communes d'Écouché et Avoine en limite de plaine.

10 Deux découvertes présentent un intérêt particulier : sur Loucé, les vestiges de quatre ou cinq bâtiments groupés suggèrent la présence d'une villa. À Joué-du-Plain, chez un particulier, des fragments de colonnes et des chapiteaux antiques ont été découverts en remploi. Ce lapidaire inégalement conservé appartient à l'ordre toscan.

11 Le bilan global des 6 années de prospection s'établit à 102 sites et indices inédits qui complètent le corpus de la base Patriarche (30 mentions). 


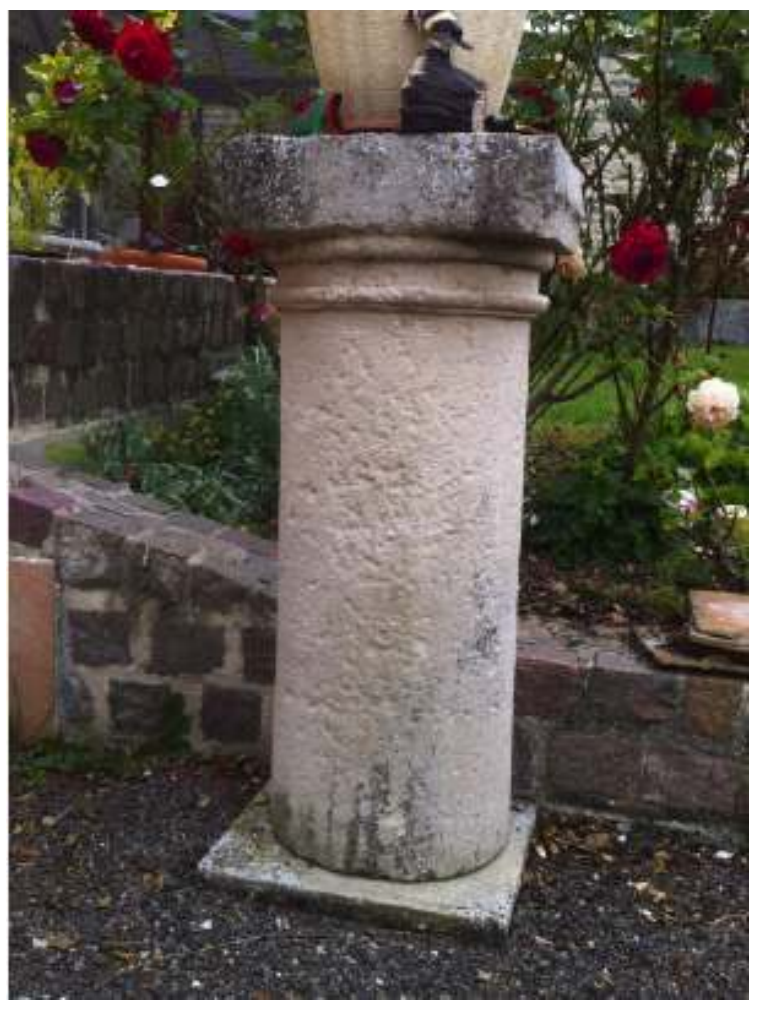

\section{Fig 01}

Lapidaire antique en remploi : base attique de colonne (inversée) à double tore Cliché : M. Lane

INDEX

Index géographique : Basse-Normandie, Orne (61)

operation Prospection thématique (PRT)

Mots-clés : villa, colonne, chapiteau

Index chronologique : Gallo-romain

\section{AUTEURS}

GUY LECLERC

BEN 